\title{
آليات تفعيل المشاركة السياسية للمرأة الجزائرية في المجالس المحلية المنتخبة
}

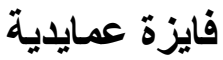 \\ كلبة الحقوق \\ جامعة العربي بن مهيدي

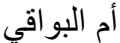

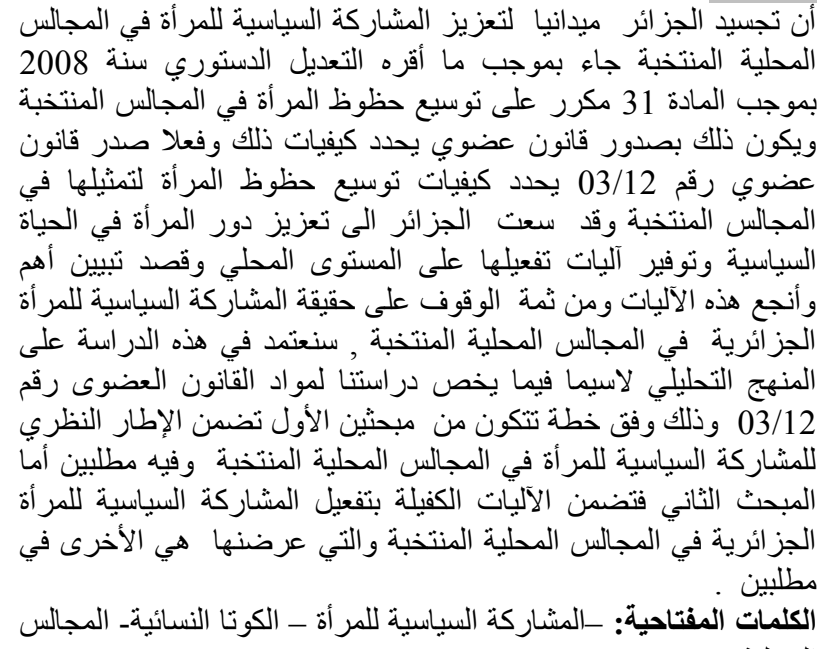

أن تجسيد الجزائر ميدانيا لتعزيز المشاركة السياسية للمر أة في المجالس

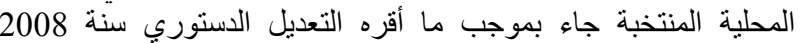

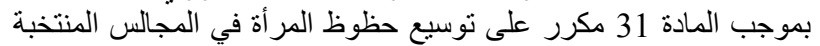

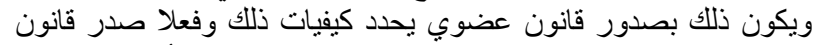

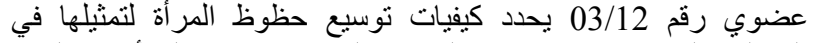

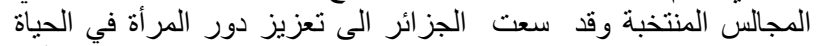

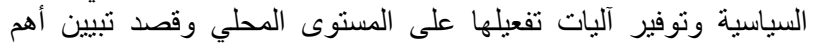

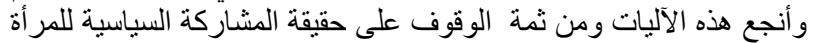

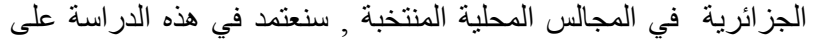

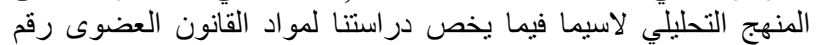

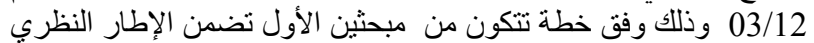

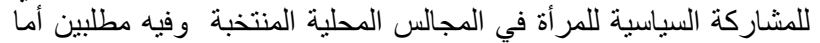

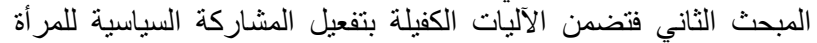

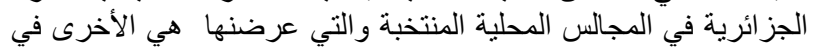
مطلبين الجزين فئرين

الكلمات المفتاحية: ـالمشاركة السياسية للمر أة ـ الكوتا النسائيةـ المجالس

المحلية

\section{مقدمة:}

إن المشاركة السياسية للمرأة في

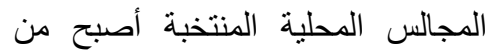

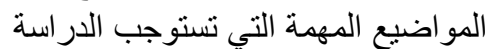

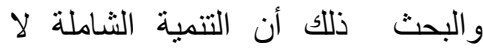

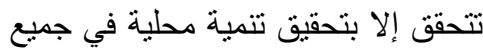

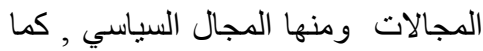

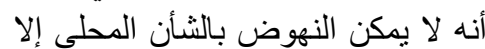

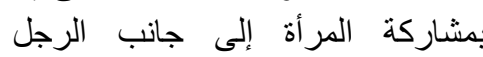

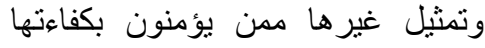

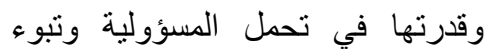

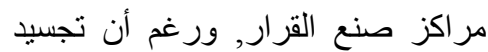
الجزائر ميدانيا للمشاركة السياسية

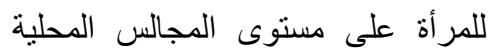

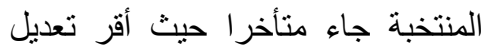

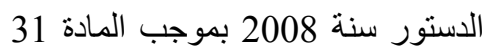
مكرر ا على توسيع حظوظ المر أة في

\section{Abstract:}

That the embodiment of Algeria in the field to promote the political participation of women in elected local councils came in accordance with the provisions of the constitutional amendment in 2008 under article 31 bis to expand the chances of women in the elected councils. This is by issuing an organic law that defines the modalities of this. Women's fortunes to represent them in the elected councils Algeria has sought to strengthen the role of women in political life and provide mechanisms for activating them at the local level and to indicate the most important and most effective of these mechanisms and to identify the reality of the political participation of Algerian women in elected local councils, In this study, we will focus on the analytical approach, especially with regard to our study of the organic law no. 12/03, according to a plan consisting of two sections. The first includes the theoretical framework for the political participation of women in the elected local councils. The second section includes mechanisms to activate the political participation of Algerian women in the councils Local elections, which were also presented in two demands.

Keywords: - Political participation of women - Women's quota - elected local councils

$$
\text { C جامعة الإخوة منتوري قسنطينة، الجز ائر C }
$$


المجالس المنتخبة ويكون ذلك بصدور قانون عضوي يحدد كيفيات ذللك وفعلا صدر قانون

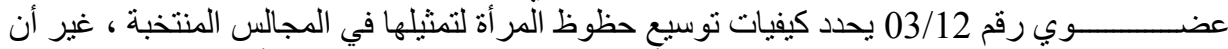

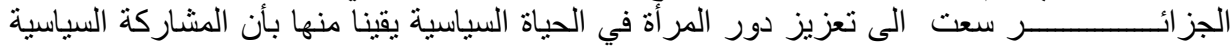

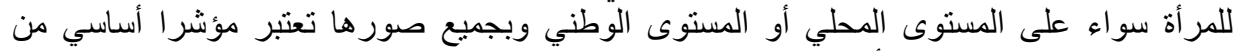

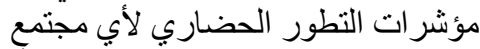

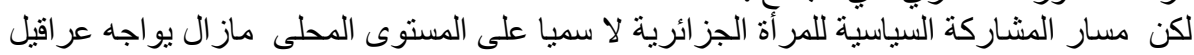

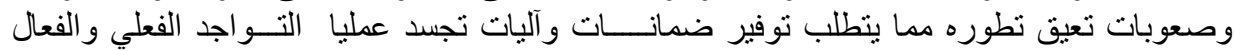

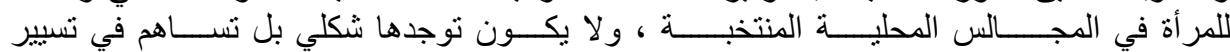

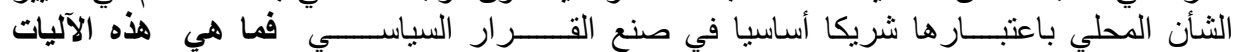

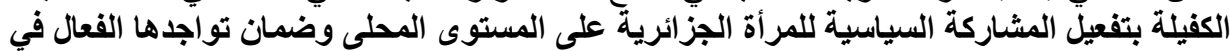

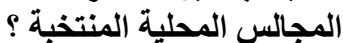

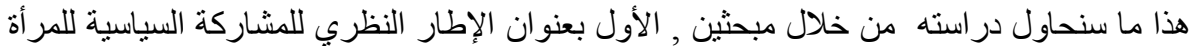

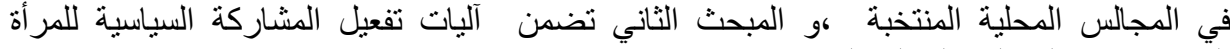

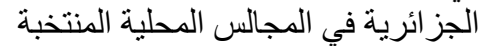

المبحث الأول: الإطار النظري للمشاركة المياسية للمرأة في المجالس المحلية المنتخبة

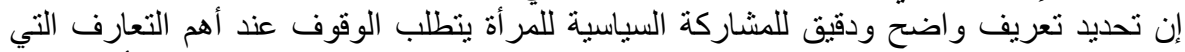

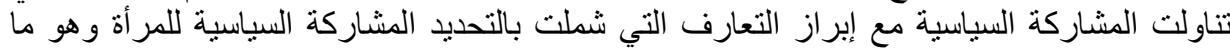

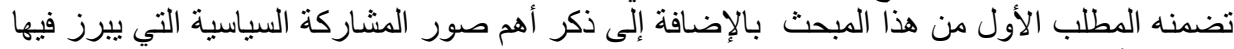

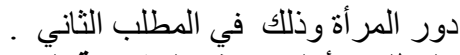
المطلب الأول:تعريف المشاركة السياسية:

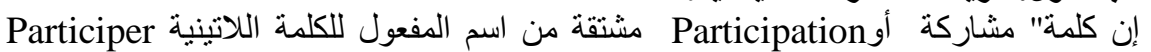

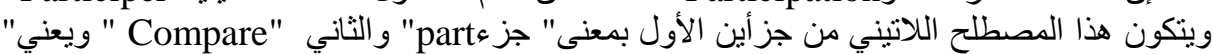

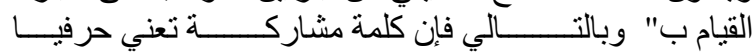
"to take part"

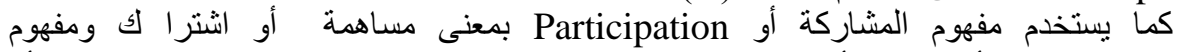
بعicicate

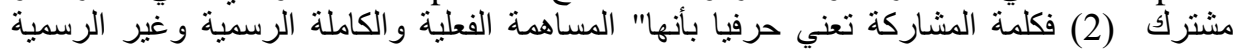

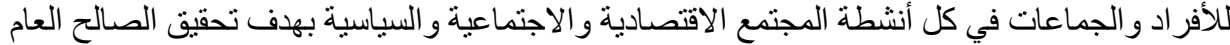

ومن هذا المعنى للمشاركة يمكن القول أن المفهوم الاصطلاحي لها يأخذ معنى إيجابيا ذو أهمية

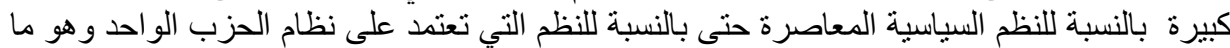

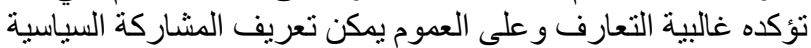

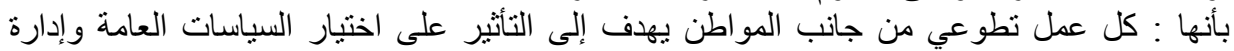

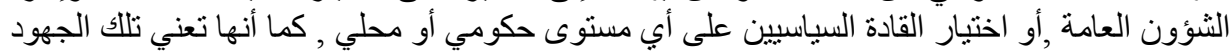

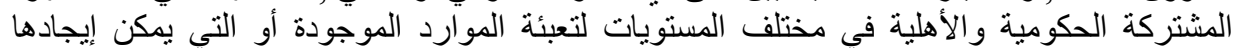

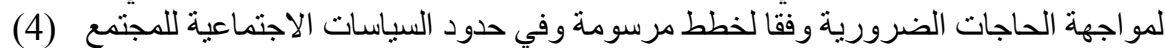

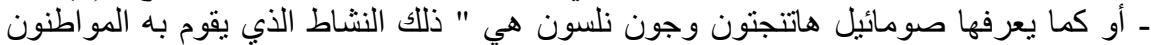

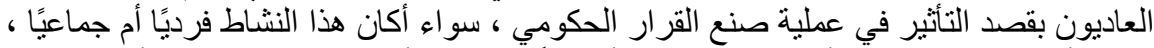

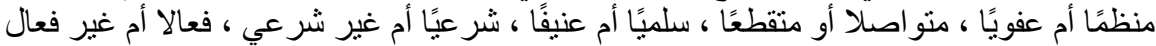

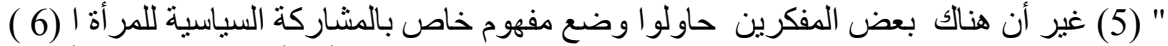

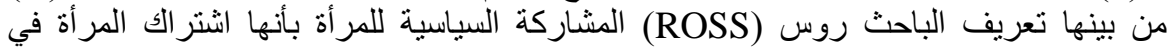


النشاطات السباسية بمختلف صور ها و أثكالها وذللك حسب ما بسمح القانون بإعطائه للمر أة من حقوق سياسية تؤهلها في الاشتر اكي العملية السياسية

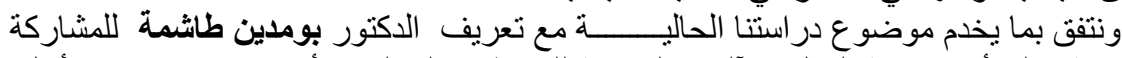

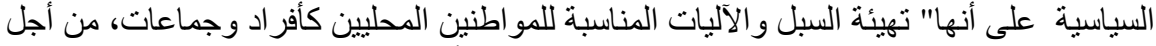

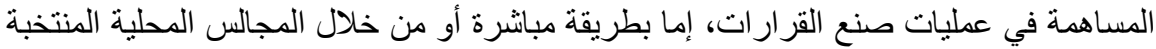

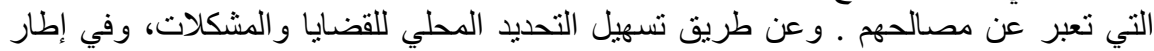

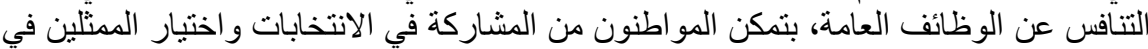

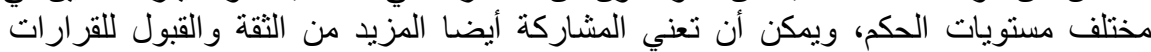

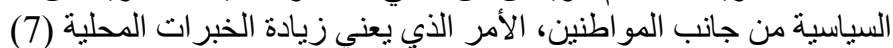

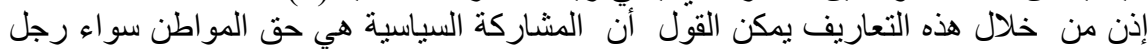

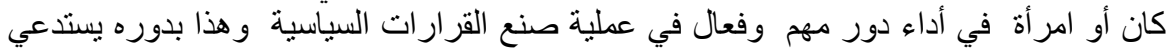

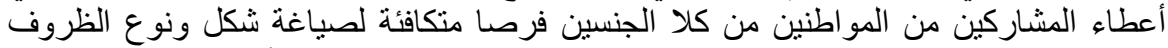

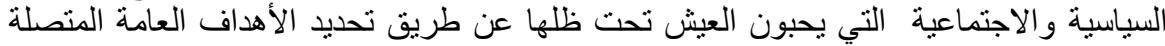

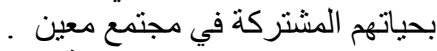
المطلب الثاني: صور المشاركة السياسية.

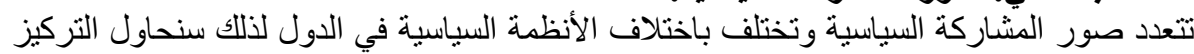
على أهمها وأكثر ها إبراز الدور المر أة في المشاركة السياسية في معظم هذه الأنظمة السياسية والتي لتئي

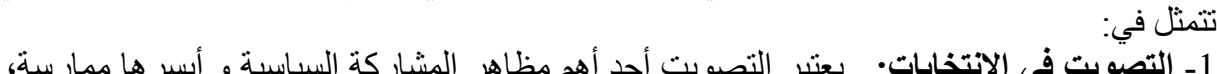

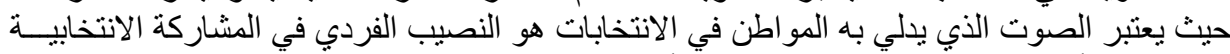

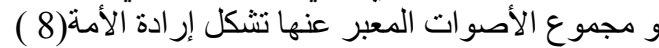

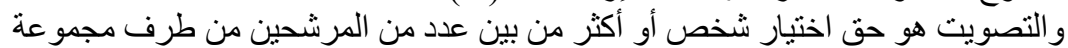

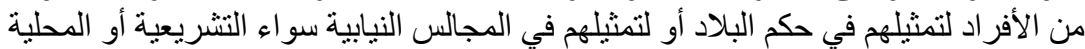

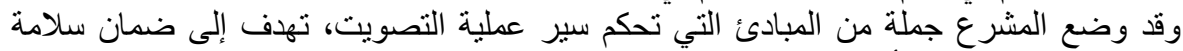

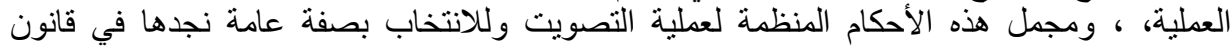

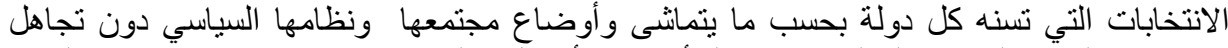

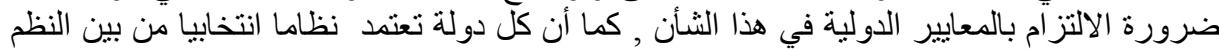

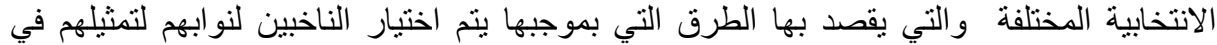

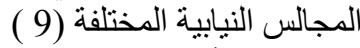

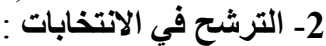

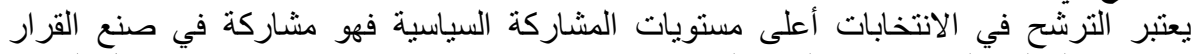

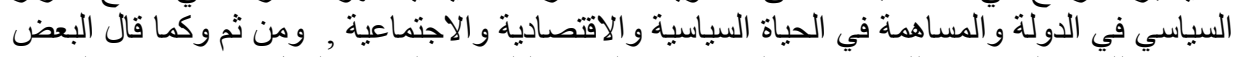

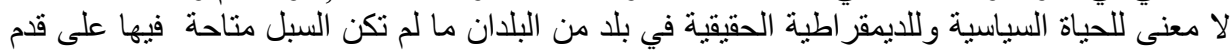

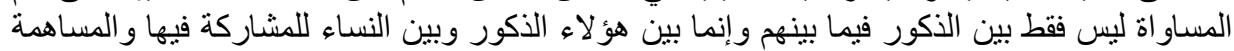

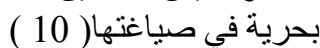

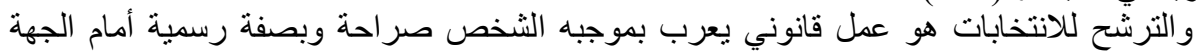

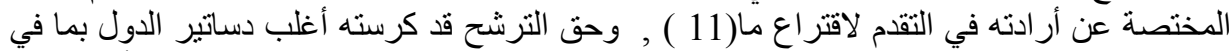

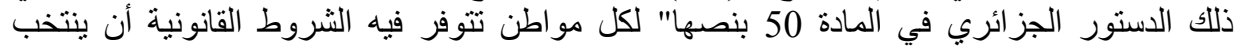

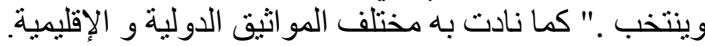

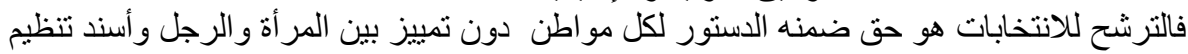

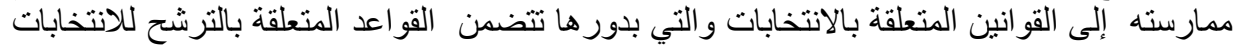
و الثروط الو اجب تو افر ها في المنر شح و الجهة التني تقبل الترشحات وتقوم عملية الترشيح على مبدأين : 
مبدأ عمومية الترشيح، بجعله متاحا لأكبر قدر من المواطنين ضمن حدود قانونية، ومبدأ إلزامية إعلان

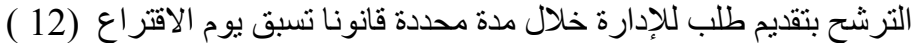

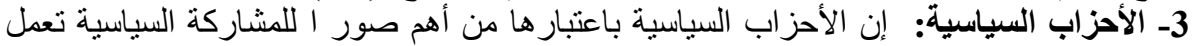

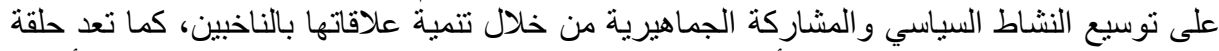

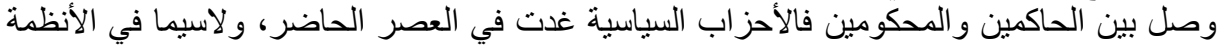

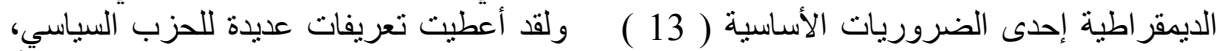

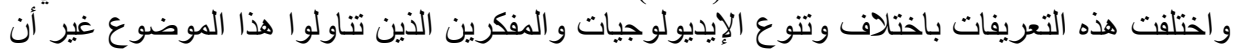

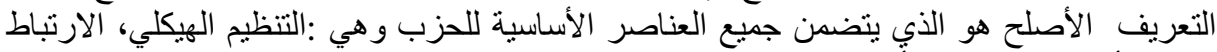

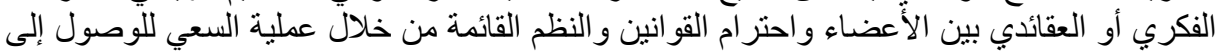
السلطة الفكري

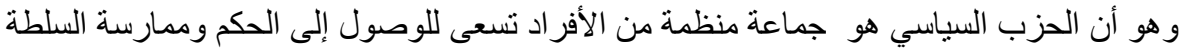

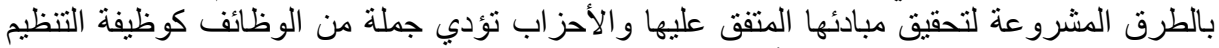

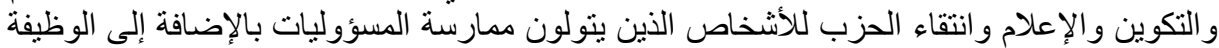

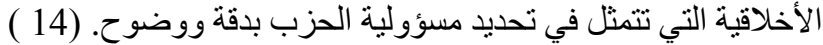

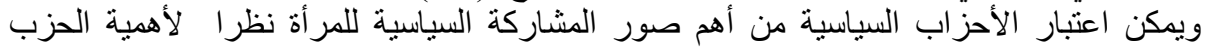

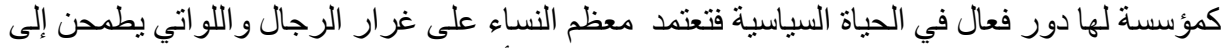

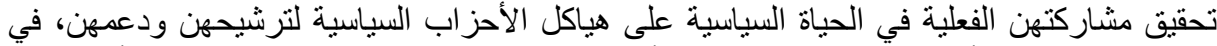

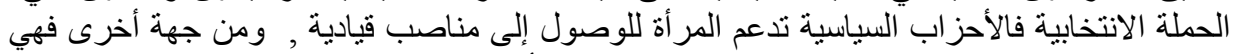

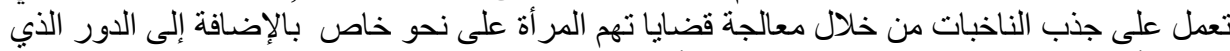

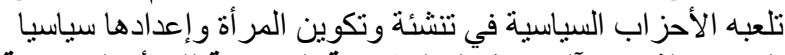

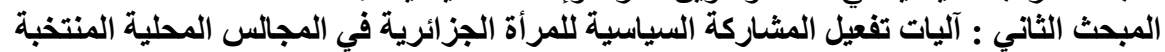

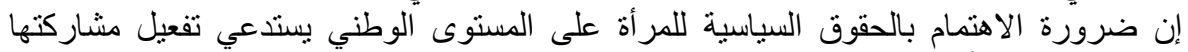

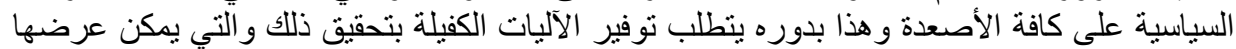

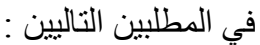
المطلب الأول : الآليات القانونية لتفعيل المشاركة السياسية للمرأة الجزائرية في المجالس المحلية المنتخبة المبة

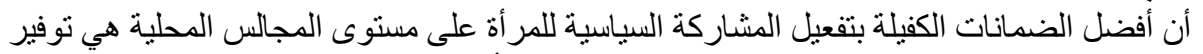

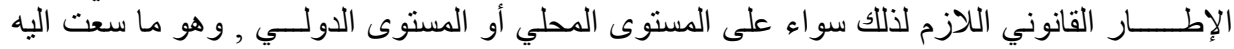

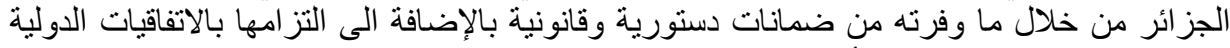

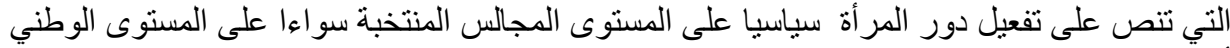

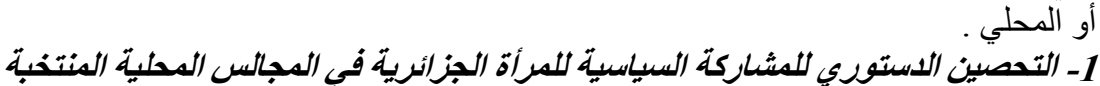

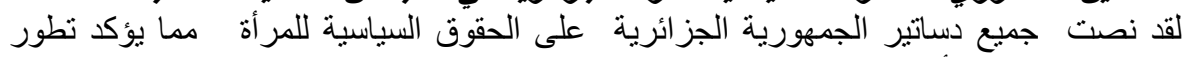

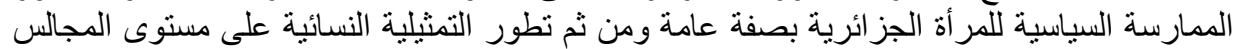

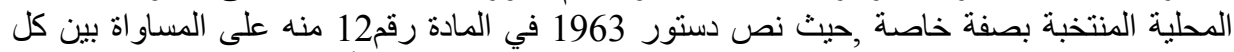

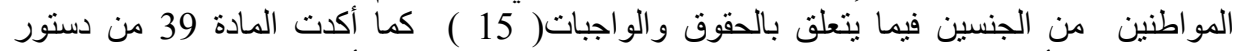

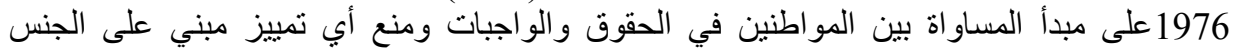

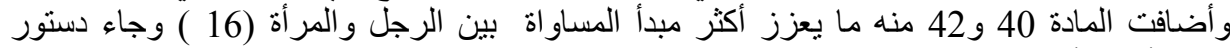

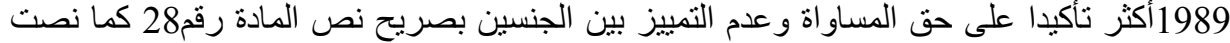

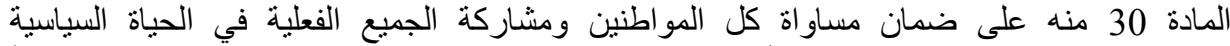

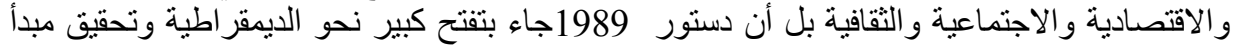

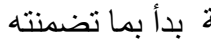
لة وغير ها من المبادئ الديمقر اطي المساو اة باعتماده التعددية الحزبي 


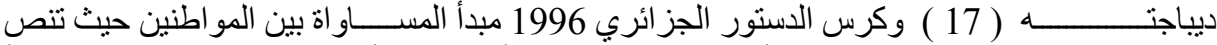

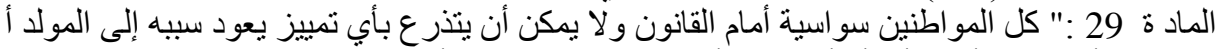

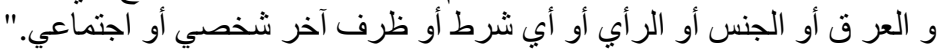

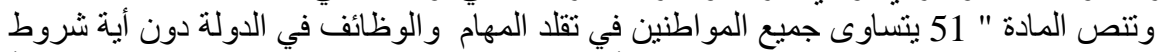

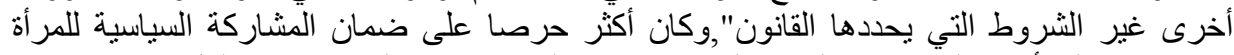

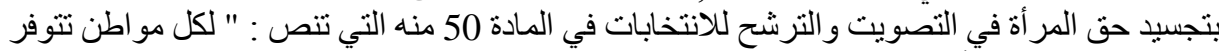

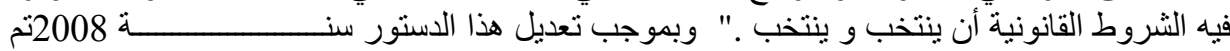

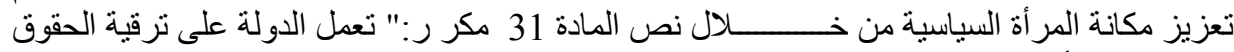

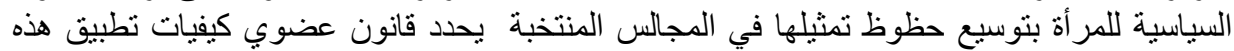

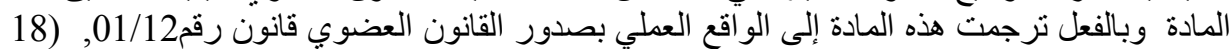

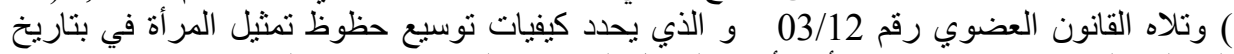

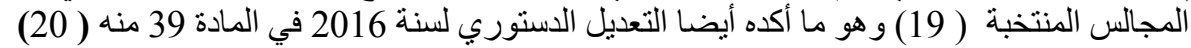
2- التزام الجزائز بالاتفاقيات الدولية القاضية بتجسيا المشاركة السياسية للمرأة في المجالس

إن الجز ائر ومنذ استقلالها بدا واضحا التزامها بكل ما بيتعلق بمبدأ المساو اة بين الجنسين وحماية

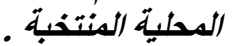

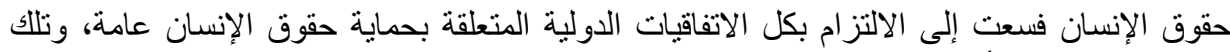

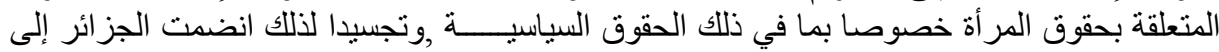

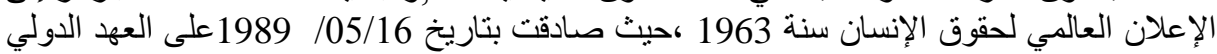

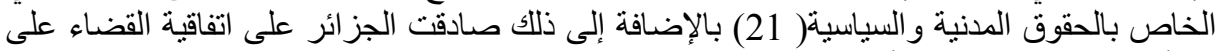

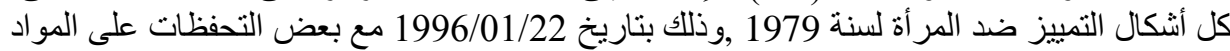

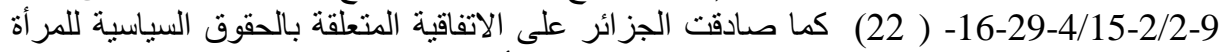

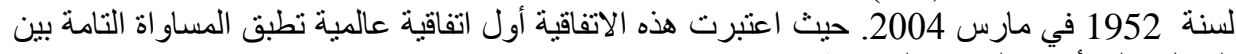

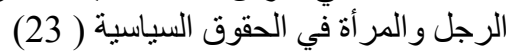

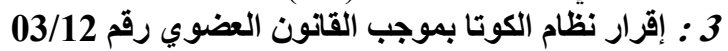

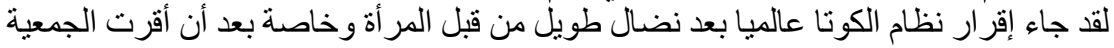

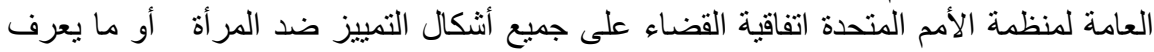

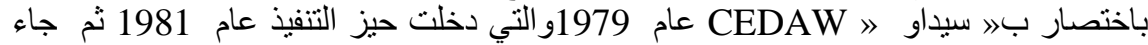
إإعلان بكين 》 ليعزز العمل على تطبيق التزامات الدول في مجال حقوق الإنسان و رفع تمثيل

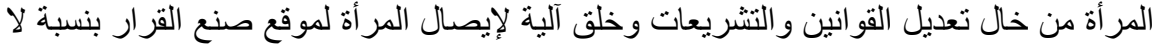
تقل عن 30 بيلوغ عام 2005 (24 ) وتمثلت هذه الآلية في نظام الكوتا .

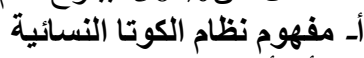

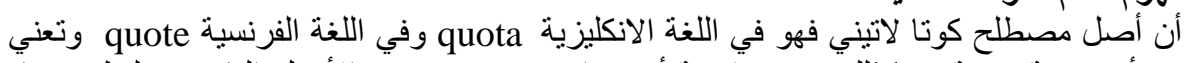

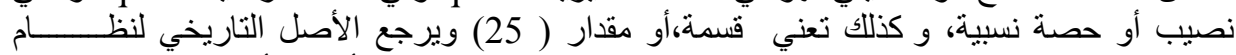

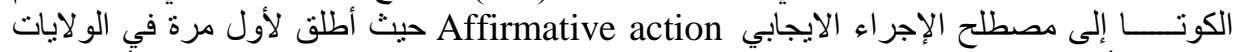

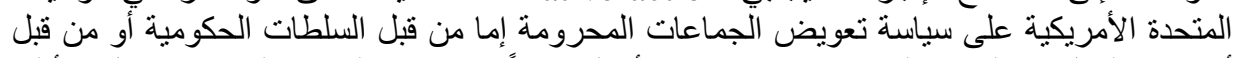

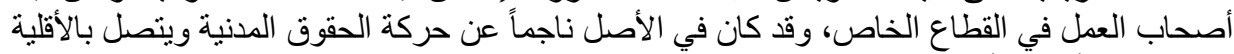

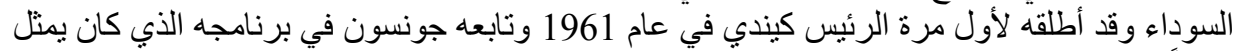

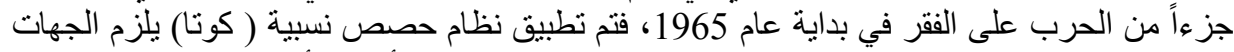

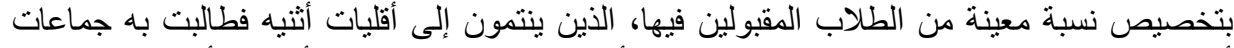

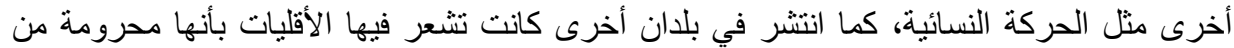

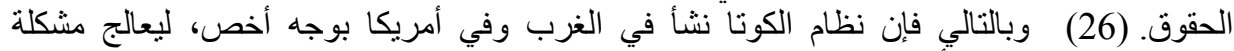

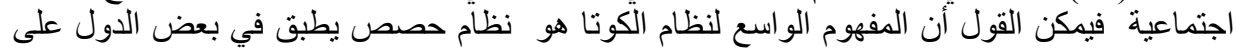


الأقليات العرقية أو الدينية أو اللغوية وتنتهجه غاليبة الأنظمة السياسية ذات الكثافة السكانية العالية

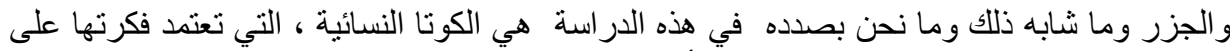

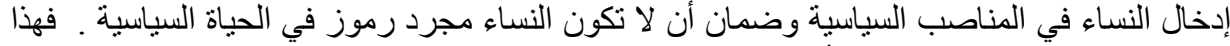

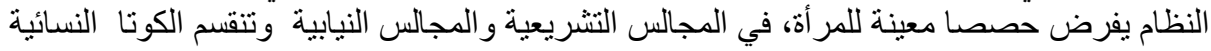
بشكل عام إلى الكوتا الاختيارية و الكوتا الإجبارية.

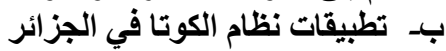

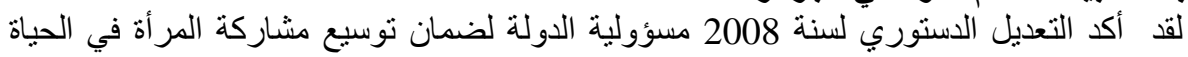

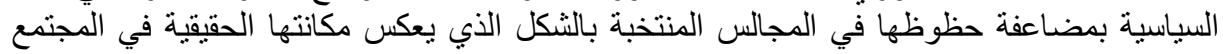

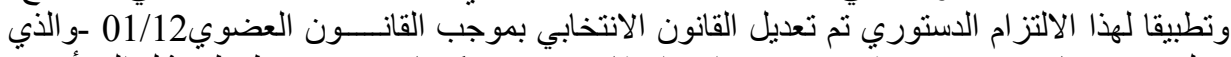

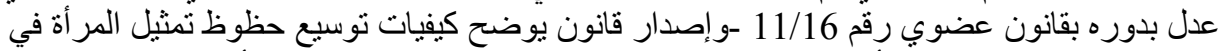

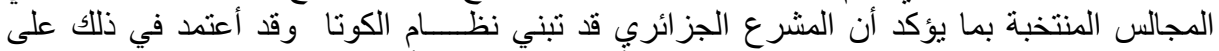

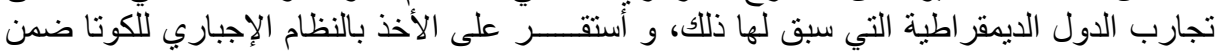

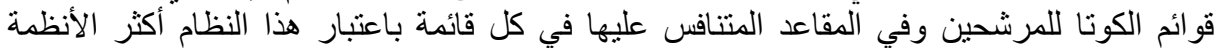

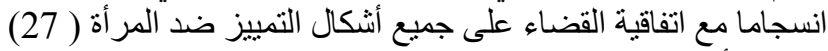

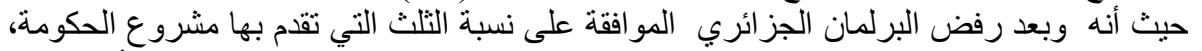

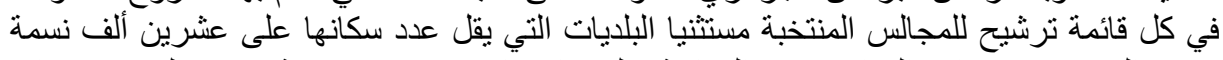

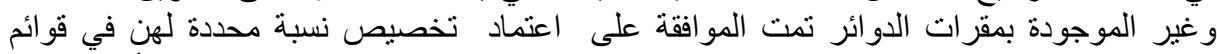

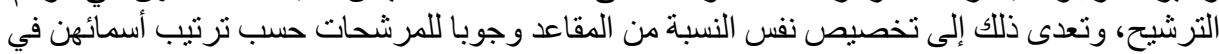

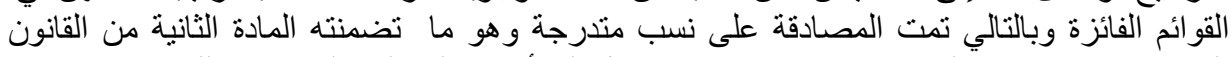

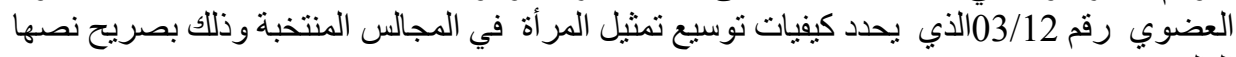

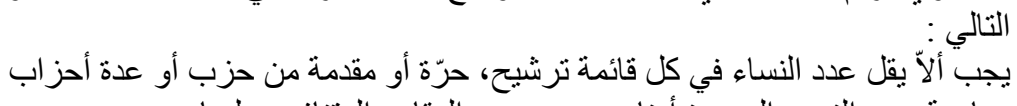

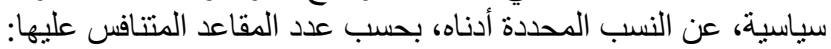
-

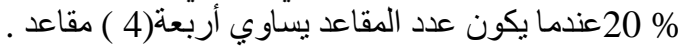

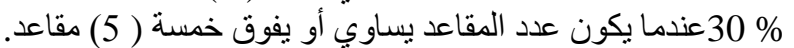

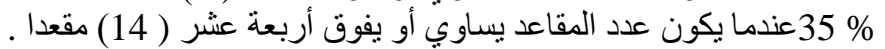

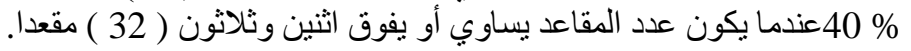

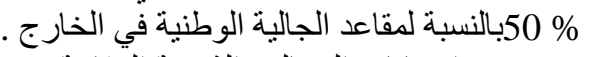
-

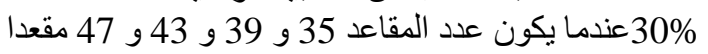
\% 35 عندما يكون عدد المقاعد 51 إلى 55 مقعدا، - 2 - م انتخابات المجالس الثعبية البلدية:

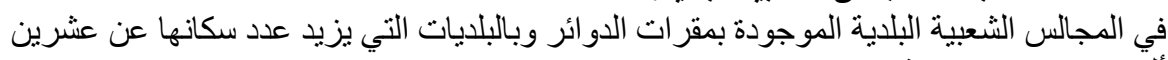
ألف (20.000 ) نسمة.

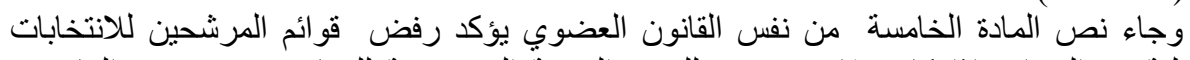

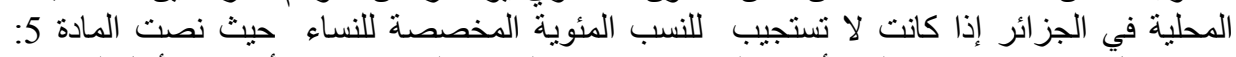

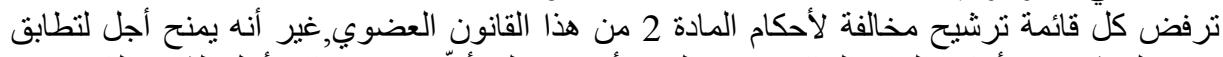

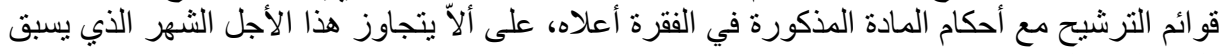

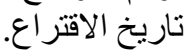

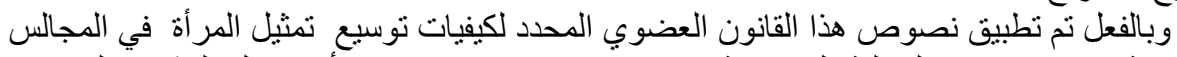
المنتخبة في الانتخابات المحلية الجزائرية بتاريخ 29 نوفمبر 2012غير أن أن إغفال المشرع الجزائر الئري 
في القانون العضوي رقم 03/12 المذكور أعلاه النص على كيفية ترتيب النساء ضمن قوائم

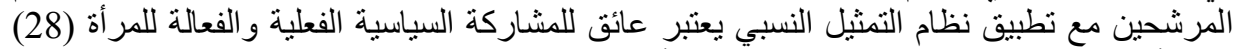

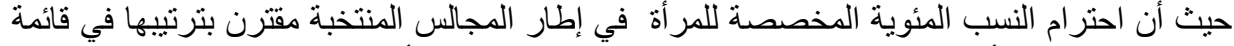

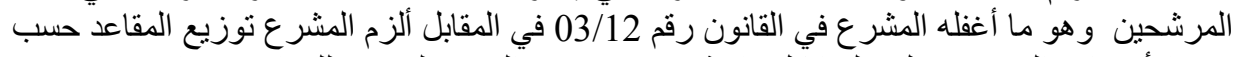

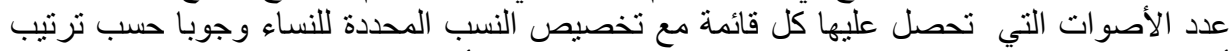

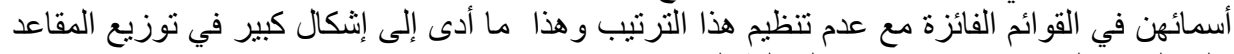

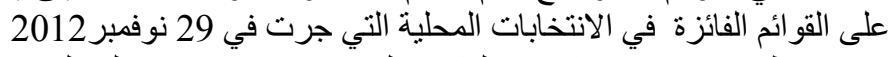

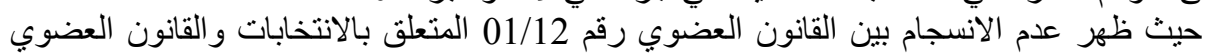

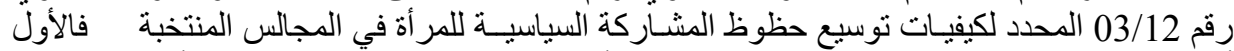

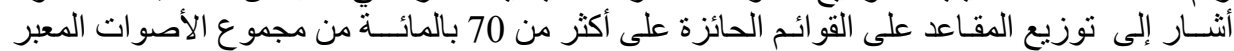

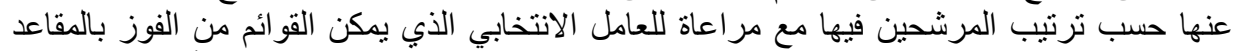

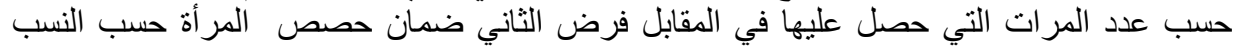

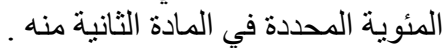

ولحل هذا الإشكال والتناقض بين القانونين تم اعتماد التعليمة الوزارية الصادرة عن وزير

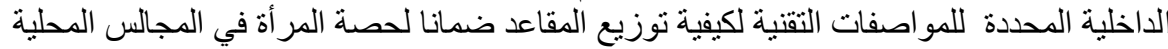

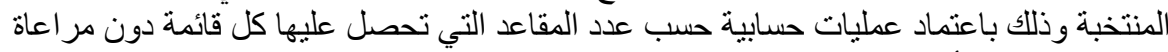

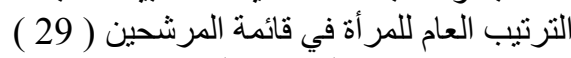

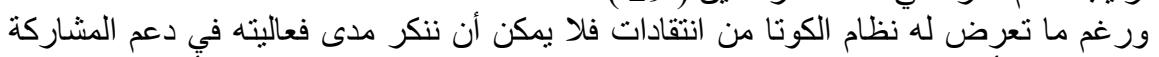

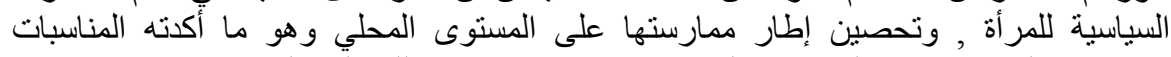

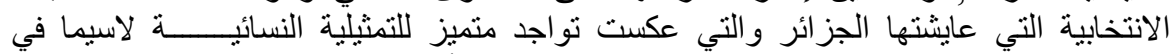

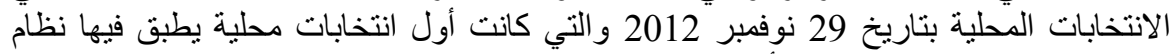

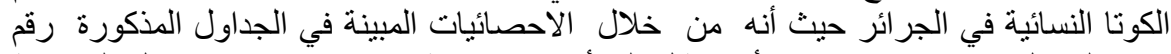

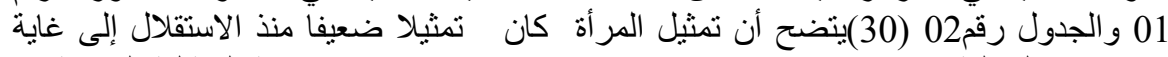

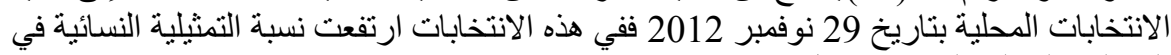

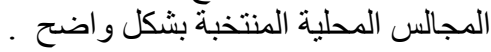




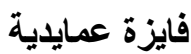

الجدول رقم 01:تطور المشاركة السياسية للمرأة في انتخابات المجلس الثعبي البلاي

\begin{tabular}{|c|c|c|c|}
\hline عدد المنتخبات & المرشبحات $\quad$ المئوية & عدد المرشحات & الانتخابات \\
\hline 20 & 1,26 & 260 & البلايلب 1967 الثعبي \\
\hline 46 & 0,6 & 96 & البلايلس 1971 الشعبي \\
\hline 160 & 2,71 & 625 & البلايلن 1975 الشعبي \\
\hline 75 & 1,09 & 1281 & البلايلن 1997 الثعبي \\
\hline 147 & 3,08 & 3679 & البلدي2002 \\
\hline 103 & I & I & البلايلس 2007 الشعبي \\
\hline 4120 & I & 32100 & البلديلس 2012 الشعبي \\
\hline
\end{tabular}

http://www.ons.dz/EMPLOI-ET-المصدر: المكتب الوطني للإحصاء في الجزائر المائ

CHOMAGE 2008.html le14/08/2017

\begin{tabular}{|c|c|c|c|}
\hline عدد المنتخبات & النسبة المئوية للمرشحات & عدد المرشحات & الانتخابات \\
\hline 45 & 9,45 & 125 & الولائي 1969 الثعبي \\
\hline I & I & 76 & الو لائي 1971 الثعبي \\
\hline 1 & 3,36 & 83 & الولائي 1975 الشعبي \\
\hline 62 & 5,10 & 905 & الولائي 1997 الشعبي \\
\hline 103 & 9,6 & 2684 & الولائي 2002 الثعبي \\
\hline 129 & 1 & 1 & الولائي 2007 الثعبي \\
\hline 595 & 1 & 8838 & الولائي 2012 الثعبي \\
\hline
\end{tabular}

http://www.ons.dz/EMPLOI-ET-المصدر :المكتب الوطني للإحصاء في الجزائر المئ

CHOMAGE 2008.html le14/08/2017 
ورغم ما تعرض له نظام الكوتا من انتقادات فلا يمكن أن ننكر مدى فعاليته في دعم المشاركة

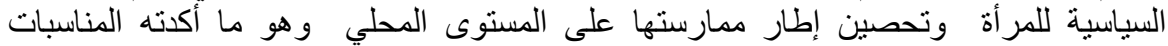
الانتخابية التي عايشتها الجز ائر و التي عكست توارئ اجد متميز للتمثيلية النسائية .

المطلب الثاني : توفير المناخ الملائم للمشاركة السياسية للمرأة الجزائرية في المجالية النية المحلية

لبعد تعرضنا لأهم الآليات القانونية لتفعيل المشاركة السياسية للمر أة في المجالس المحلية المنتخبة

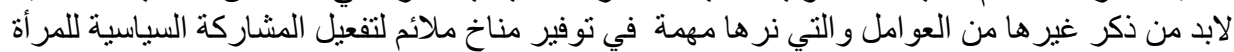

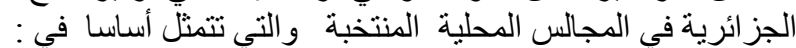

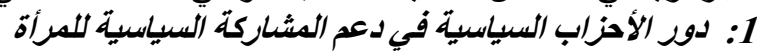

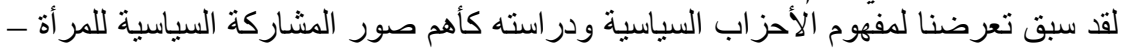

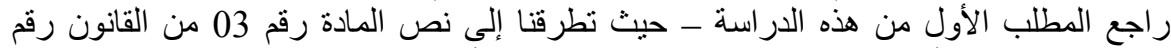

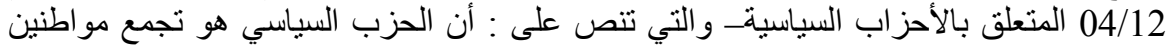

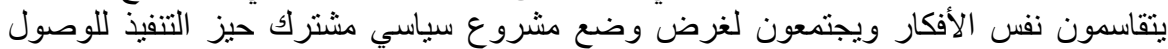

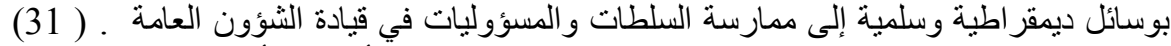

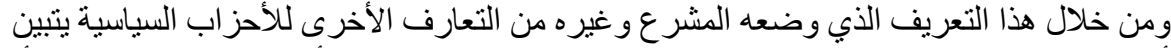

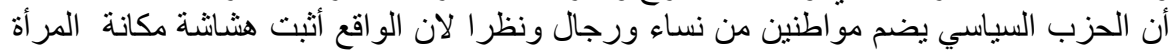

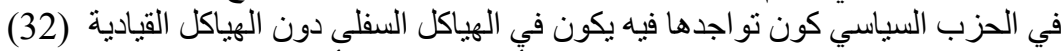

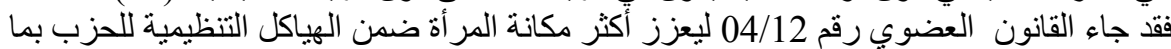

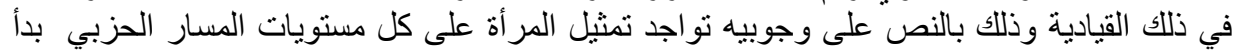

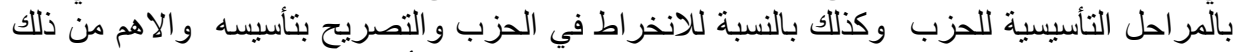

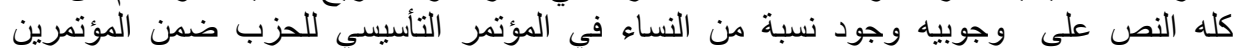

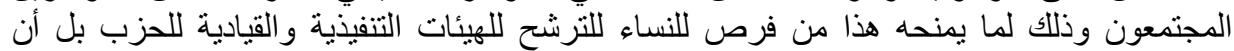

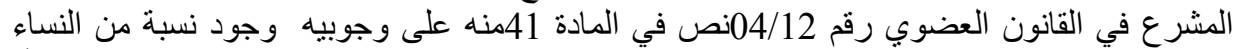

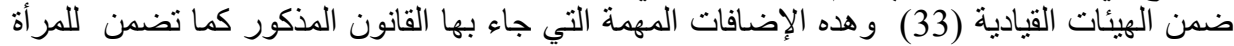

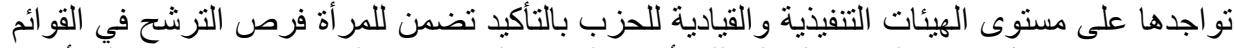

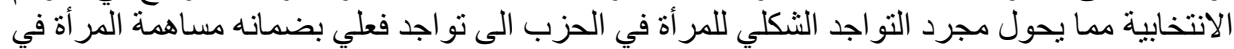

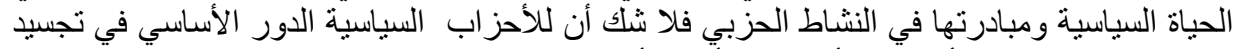

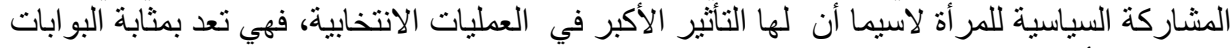

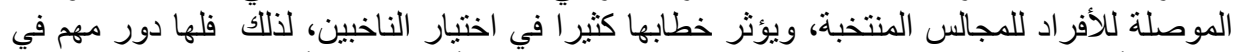

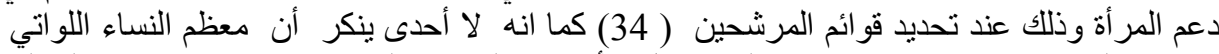

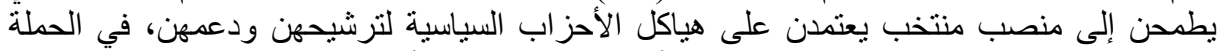

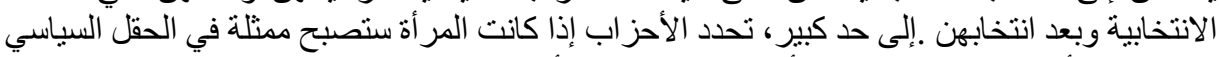

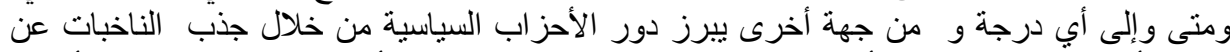

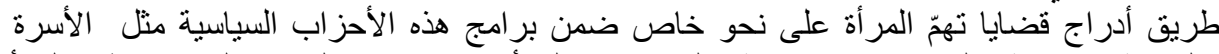

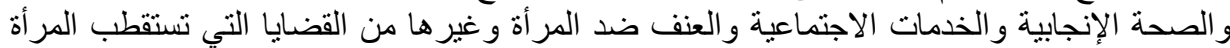
الى الحياة السياسية (35) (35)

2 - بناء ثقافة مجتمعية مساندة لمشاركة المرأة سياسيا:

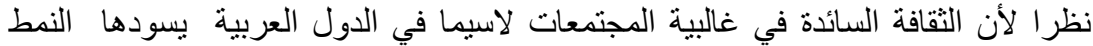

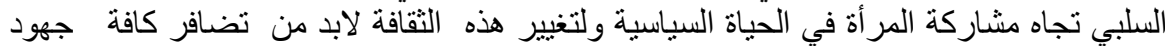

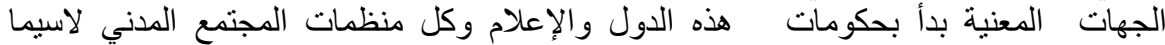


الجمعيات و المنظمات النسائية والأخذ بعين الاعتبار التركيز على الجو انب المؤثرة في تغيير ثقافة

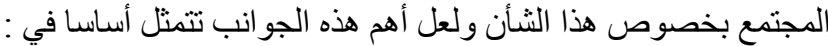

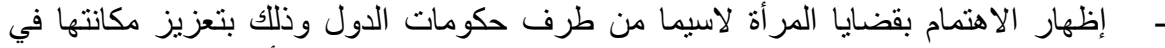

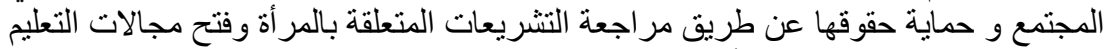

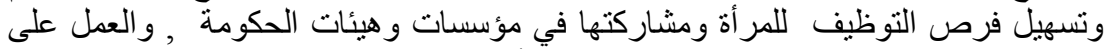

تهيئة بيئة ديمقر اطية مستقرة تضمن مشاركة المر أة في الحياة العامة (

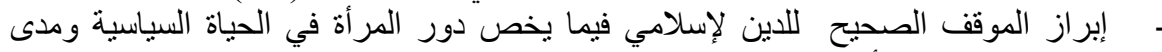

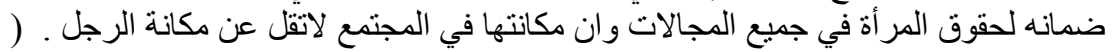

ـ ـ ـ توضيح الآثار الإيجابية المترتبة على مشاركة المر أة في تسيير الثؤون العامة للمجتمع لاسيما

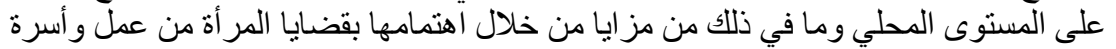
وتعليم......

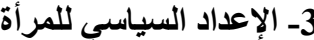

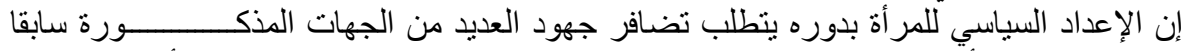

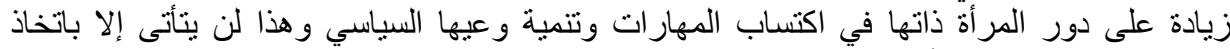

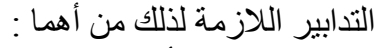
- إعداد وتأهيل النساء اللاني بر غبنا في الترشح للانتخابات من خلال برامج تدريبية معدة لذللك

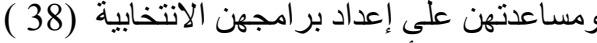

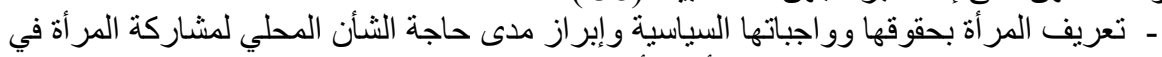

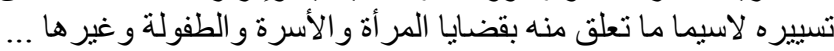

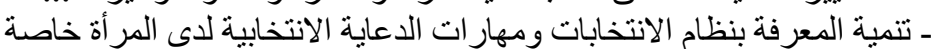

الخاتمة أنمة

لوأن أهم ما ننتهي إلى قوله أن واقع تمثيل المرأة الجزائرية على مستوى المجالس المحلية المنتخبة

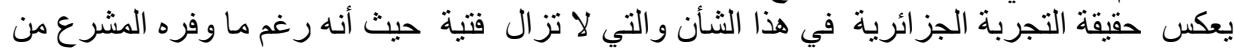

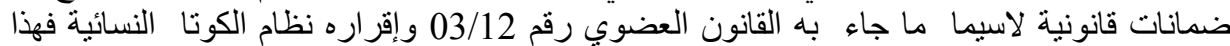

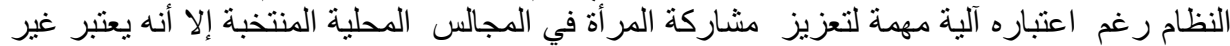

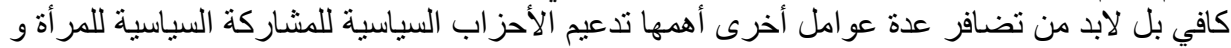

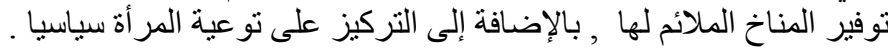

\section{قائمة الهو امش و المراجع}

1- ارق محمد عبد الوهاب، سيكولوجية المشاركة السياسية، دار غريب للطباعة والنشر والتوزيع،

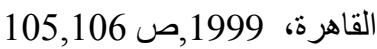

2- د: أحمد محمد يوسف غنايم , تفعيل دور المرأة في المشاركة السياسية , ط1 , المركز القومي

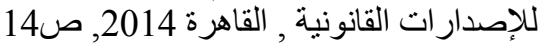

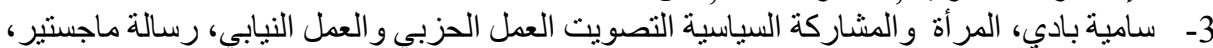

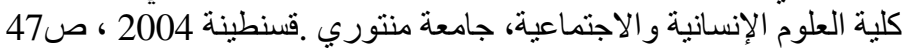

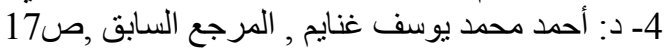
5-د: ايمان بييرس , المشاركة السياسية للمر أة في الوطن العربي , جمعية نهوض وتتمية المرأة , مصر

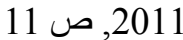
6د : صالحة سهيل العامري , دور المر أة الإمار اتية في المشاركة السياسية , مذكرة ماجستير , جامعة

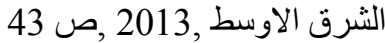


7- بومدين طاثمة، الحكم الر اثد ومشكلة بناء قدرات الإدارة المحلية في الجزائر،امجلة ,التواصل ،

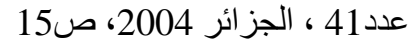

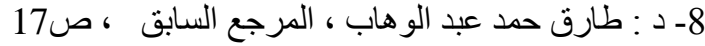

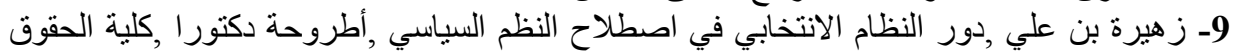

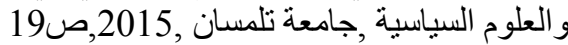
10-د: حسام فرحات أبو يوسف , الحماية الدستورية للحق في الدساو اة-دراسة مقارنة ــرسالة دكتورا

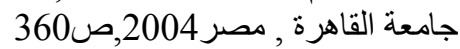

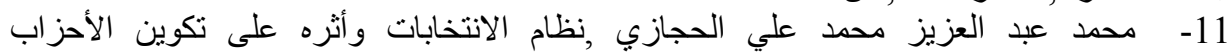

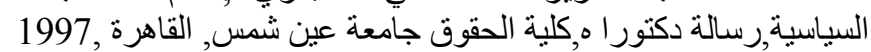

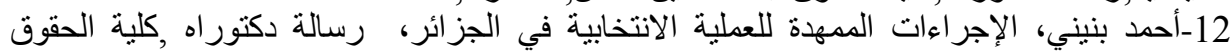

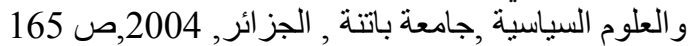

13- منير محمد البياتي ، النظـــــام السياسي الإسلامي مقارنا بالدولة القانونية ، ط2 ، دار النشر عمان

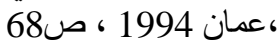

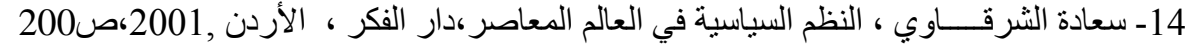

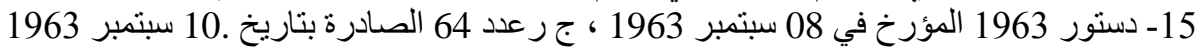
16 - دستور 1976 ، المؤرو خ في 22 نوفمبر 1976 ، 1976 ، الجريدة الرسمية عدد90 الصنادرة في 17 نوفمبر

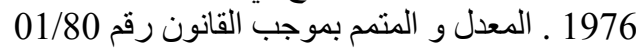
18 - ديباجة دستور الجمهورية الجز ائرية الديمقرطية الثنعبية , المؤرخ في 43 فبر اير سنة 1989 ،جرد عدد 9 الصادر بتاريخ1 مارس 1998 19- القانون العضوي رقاريخ مارئ 01/12 المؤرخ في 12 يناير 2012 و التعلق بنظام الانتخابات الجريدة

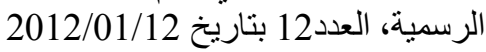

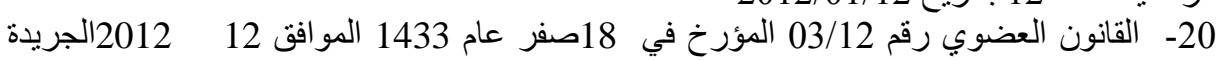

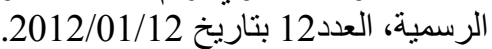

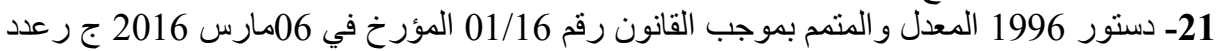
14 الصنادرة بتاريخ 07مارس 216

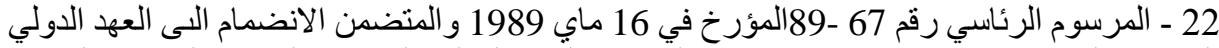

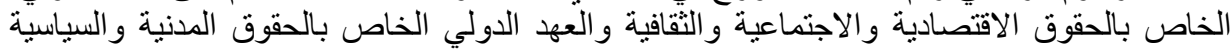

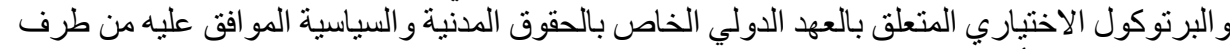

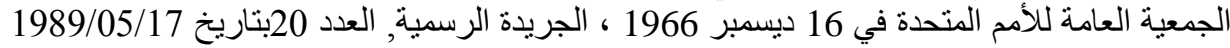

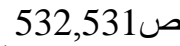

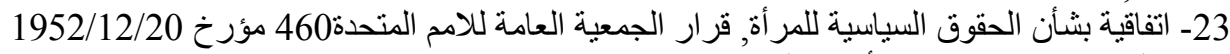
تاريخ النفاذ 1954/7/7 وفقان الأحكام المادة 49 منها 24- د: وصال نجيب العزاوي , المرأة العربية والتغيير السياسي , ط1, دار أسامة للنشر والتوزيع ,

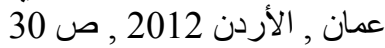
25 - د,عمار بوضياف": نظام الكوتا كآلية لترقية الحقوق السياسية للمر أة وموقف التشريعات العربية

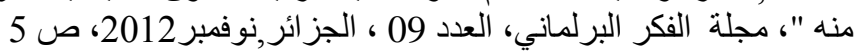

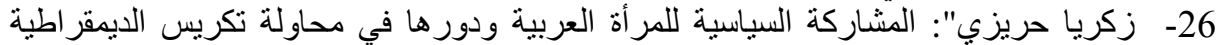

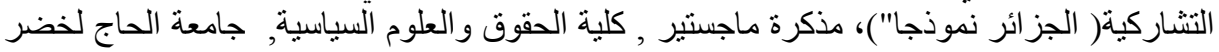

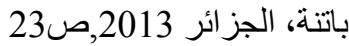

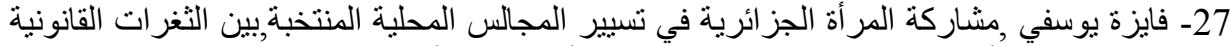

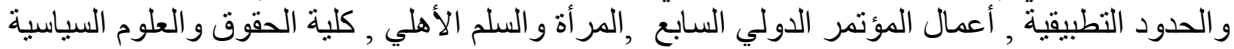

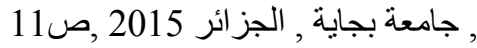




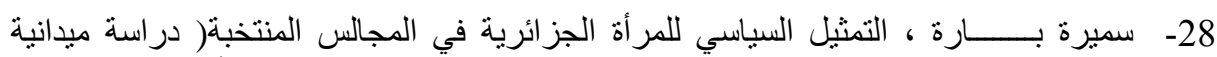

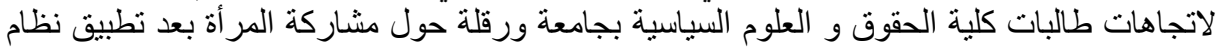

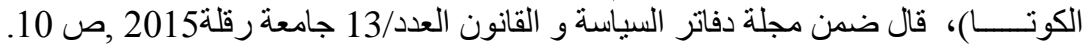

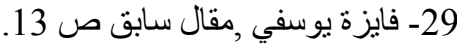

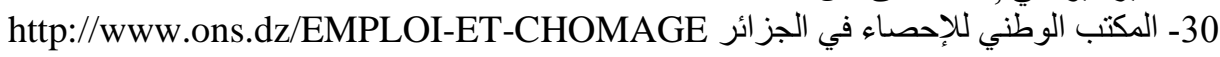
2008.html le14/08/2017 31 - المادة رقم 03 من القانون العضوي رقم 04/12 المؤرخ في 18 صفر 1433الموافق 12يناير

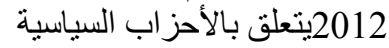

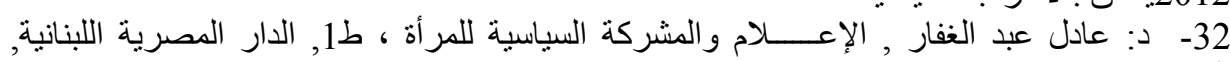

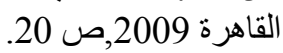

33- القانون العضوي رقم 04/12 المؤرخ في 18 صفر 1433المو افق 12يناير 2012 20نتعلق بالأحزاب

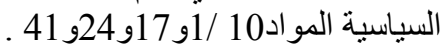
34- سامية بادي ، المر أة و المشاركة السياسية: التصويت ,العمل الحزبي ,العمل النيابي ، مذكرة لنيل

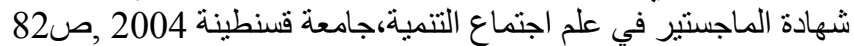

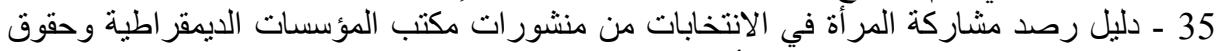

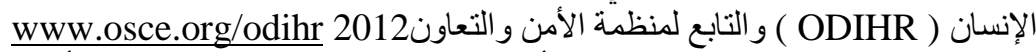
36- د: وصال نجيب العـــــزاوي ,المر أة العربية والتغيير السياسي , ط1, دار أسامة للنشر و التوزيع

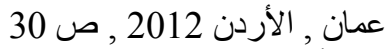

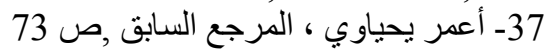
38- د: وصيال نجيب العز اوي مرجع سابق , ص 32 